\title{
Difficult Airway Prediction Score for Intubation in Emergency Departments: A Retrospective Cohort Study
}

Sorravit Savatmongkorngul

Mahidol University

Panrikan Pitakwong

Mahidol University

Pungkava Sricharoen

Mahidol University

Chaiyaporn Yuksen ( $\nabla$ chaipool0634@hotmail.com )

Mahidol University

Chetsadakon Jenpanitpong

Mahidol University

Sorawich watcharakitpaisan

Mahidol University

\section{Research Article}

Keywords: predictive model, airway assessment score, difficult intubation

Posted Date: November 30th, 2021

DOI: https://doi.org/10.21203/rs.3.rs-1087598/v1

License: (9) (i) This work is licensed under a Creative Commons Attribution 4.0 International License. Read Full License 


\section{Abstract}

Objective: Difficult intubation is associated with an increasing number of endotracheal intubation attempts. Repeated endotracheal intubation attempts are in turn associated with an increased risk of adverse events. Clinical prediction tools to predict difficult airway have limited application in emergency airway situations. This study was performed to develop a new model for predicting difficult intubation in the emergency department.

Methods: This retrospective study was conducted using an exploratory model at the Emergency Medicine of Ramathibodi Hospital, a university-affiliated super-tertiary care hospital in Bangkok, Thailand. The study was conducted from June 2018 to July 2020. The inclusion criteria were an age of $\geq 15$ years and treatment by emergency intubation in the emergency department. Difficult intubation was defined as a Cormack-Lehane grade III or IV laryngoscopic view. The predictive model and prediction score for detecting difficult intubation were developed by multivariable regression analysis.

Results: During the study period, 617 patients met the inclusion criteria; of these, 83 (13.45\%) had difficult intubation. Five independent factors were predictive of difficult intubation. The difficult airway assessment score that we developed to predict difficult airway intubation had an accuracy of $89 \%$. A score of $>4$ increased the likelihood ratio of difficult intubation by 7.62 times.

Conclusion: A difficult airway assessment score of $>4$ was associated with difficult intubation.

\section{Background}

Endotracheal intubation remains the gold standard for emergency airway management, providing oxygenation, ventilation, and airway protection from aspiration in acutely ill patients. The use of neuromuscular blocking agents is often required to encourage optimal visualization of glottic structures and improved intubation success. However, apnea caused by intubation failure may result in oxygen desaturation, which can increase morbidity and mortality. ${ }^{1-3}$ Therefore, predicting a difficult airway is important to assist with risk-benefit analysis and establish the optimal approach to airway management.

In the emergency department (ED), emergency physicians (EPs) are responsible for managing airway problems. Emergency intubation is more complicated than elective intubation in the operating room setting because the clinical condition of acutely ill patients in the ED is unpredictable and the setting is less controlled. ${ }^{4-6}$ The proportion of difficult intubation ranges from $10-27 \%$ in the ED setting ${ }^{7-10}$ but from only $1-9 \%$ in the anesthesia setting. ${ }^{11-13}$ The incidence of difficult intubation increases with the number of intubation attempts. ${ }^{14}$ Repeated intubation attempts increase the risk of adverse events such as cardiac arrest, arrhythmia, regurgitation, and airway trauma. ${ }^{14-16}$ Early recognition of difficult intubation is helpful for early detection and preparation for further management. 
Many large multicenter studies have provided data on emergency airway management in the ED. 8,9,14,17 One study demonstrated that predicted airway difficulty was the main factor associated with successful intubation on the first attempt. ${ }^{17}$ Although various difficult airway prediction tools have been proposed and evaluated, each has limitations in terms of its sensitivity and specificity. ${ }^{8,17-21}$ Difficult airway assessment tools such as "LEMON" (Look externally, Evaluate the 3-3-2 rule, Mallampati score, Obstruction, Neck mobility) combine intuitive elements (e.g., "look externally") with assessments developed in the operative setting that require the patient to be awake and cooperative. ${ }^{8}$ The main objective of the present study was to develop and validate a model for predicting difficult intubation in patients undergoing emergency tracheal intubation in the ED. Clinical factors associated with difficult intubation were evaluated, and the scores used to predict difficult intubation by simple physical evaluation were examined. Such a predictive score is expected to be of benefit to community or general hospitals that do not have EP specialists. This difficult airway prediction score will expedite treatment and help anesthesiologists and otolaryngologists to prepare for difficult intubation or transfer the patient to a suitably equipped hospital.

\section{Methods}

\section{Study design}

This was a diagnostic, retrospective cohort study using an exploratory model. It was conducted at the ED of Ramathibodi Hospital, a university-affiliated super-tertiary care hospital in Bangkok, Thailand. The data were collected from the Ramathibodi Hospital database and emergency medical record system from June 2018 to July 2020.

\section{Sample size}

The data were collected from June 2018 to July 2020 and analyzed by STATA version 16.0 (StataCorp, College Station, TX, USA). A pilot study was performed to calculate the sample size by employing a twosample comparison of difficult intubation and non-difficult intubation. Using the formula $N=Z a / 22 p(1-$ p) $/ d^{2}$, standard normal variate $(\mathrm{Za} / 2)$ at $1 \%$, probability of the expected value $(\mathrm{p})=0.12$, and a two-sided test, the minimum sample size was determined to be 281 patients.

\section{Participants}

Patients were required to be $>15$ years of age and to have undergone emergency intubation in the ED. We excluded patients who had been intubated by a non-EP (general practitioner) and those who had developed cardiac arrest. From the minimum sample, 281 patients who underwent emergency intubation in the ED were enrolled in this study. The study period was 2 years (from June 2018 to July 2020).

\section{Definition of difficult intubation (reference standard)}


The definition of difficult intubation was the same as that of difficult laryngoscopy, according to the structures that can be visualized and identified by laryngoscopy. Using the four-grade classification of the laryngoscopic view defined by Cormack and Lehane, ${ }^{22}$ intubation was defined as easy (grade I or II) or difficult (grade III or IV). The laryngoscopic view was assessed and graded according to the final intubation after each intubation was finished.

\section{Definitions of predictors}

\section{Intubation method}

An "intubation method" was defined as one set of medication or devices, such as rapid-sequence intubation with direct laryngoscopy.

\section{Intubation attempt}

An "intubation attempt" was defined as one effort to place an airway. Each attempt could be performed using one or more methods, and each method could have one or more attempts. After each intubation was finished, the clinician entered all data in the medical record form.

\section{Operator level}

We classified the operator's level of training into three groups: low experience (general practitioners), moderate experience (first-year residents in emergency medicine and first-year residents in general medicine), and high experience (second- to third-year residents in emergency medicine and emergency attending staff).

\section{Failed intubation}

We defined "failed intubation" as multiple efforts to place an airway (more than one effort).

\section{Indicators of difficult intubation}

The difficult intubation assessment tool "LEMON" and difficult ventilation assessment tool "MOANS" (Mask seal, Obesity, Age (elderly), No teeth, Stiffness) were used to evaluate the patients undergoing endotracheal intubation. 8,18 For the "Look externally" criterion of "LEMON," we assessed any significant facial injury, large incisors, significant beard or mustache, and large tongue. For the "Evaluate the 3-3-2 rule" criterion, we assessed a mouth opening of less than three finger breadths, a hypomental distance of less than three finger breadths, and a thyrohyoid distance of less than two finger breadths. For the "Obstruction" criterion, we record all conditions that may make the laryngoscopic view more difficult, such as a mass, hematoma, or massive bleeding. For the "Neck mobility" criterion, we assessed limited neck mobility, such as collar immobilization. With respect to the "Mallampati score" criterion of the "LEMON" assessment tool, however, we did not record the Mallampati score because it requires patient cooperation, which is limited in critically ill patients in the ED. Indicators of difficult intubation using the "MOANS" 
assessment tool were also noted, but we did not consider them as indicators of difficult intubation in this study.

\section{Data collection and study variables}

We collected data regarding the patients' characteristics, including sex, age, Glasgow coma scale score, main indication for intubation, initial method of intubation, dosage of any medications used, operator level of training, number of attempts, success or failure, and structures identified by direct and indirect laryngoscopy. The patients were divided into two groups: the difficult intubation group and the nondifficult intubation group. We then used a multivariable regression model to identify significant predictors of difficult intubation. The data were collected from June 2018 to July 2020, and after excluding patients who did not meet the study criteria, the total sample size was 617 patients. The protocol is illustrated in Figure 1.

\section{Outcome of interest}

The outcome of interest was a positive difficult anatomical laryngoscopic view according to the final intubation after each set of intubation attempts was finished. Patients in the difficult intubation group had a Cormack-Lehane grade III or IV laryngoscopic view, and those in the non-difficult intubation group had a Cormack-Lehane grade I or II laryngoscopic view. Finally, we used the patients' data to develop a risk score with which to predict difficult intubation in the ED.

\section{Statistical analysis}

The data were analyzed using STATA version 16.0 (StataCorp). All variables were compared between the difficult intubation and non-difficult intubation groups by descriptive statistics. The predictive power of each variable for a positive difficult laryngoscopic view was calculated using univariable logistic regression and is presented as the area under the receiver operating characteristic curve (AuROC) with the 95\% confidence interval (Cl). A multivariable stepwise backward logistic regression model was used to develop the predictive model. Predictors with a cut-off P-value of 0.05 after the univariable analysis were included in the model and eliminated with a significance level of 0.001 . Regression coefficients for each level of each clinical predictor were divided by the smallest coefficient of the model and rounded to the nearest 0.5 , resulting in an item risk score. According to this score, the coefficients were then changed into item scores and added together into a single score, and the patients were thus classified into low-, moderate-, and high-probability categories. Discrimination of the airway assessment scores is presented as the AuROC and $95 \% \mathrm{Cl}$ for the clinical risk score of difficult intubations. Calibration of the prediction was performed using the Hosmer-Lemeshow goodness-of-fit test. The score-predicted risk of difficult intubation and the observed risk were then compared in a graph. The number of reports and percentages of each group are presented with the positive likelihood ratio, 95\% Cls, and P-values.

\section{Results}


A total of 790 patients underwent emergency endotracheal intubation in the ED of Ramathibodi Hospital. We excluded patients intubated by general practitioners $(n=80)$, patients who developed cardiac arrest $(n$ $=75)$, and patients with incomplete data $(n=18)$. The remaining 617 intubations were included in the analysis.

The patients' overall baseline characteristics are presented in Table 1. Their mean age was 68.66 years, and $56.56 \%$ were male. The proportion of men was significantly higher in the difficult intubation group than in the non-difficult intubation group $(63.86 \%$ vs. $55.43 \%$, respectively; $P=0.155)$. The proportion of patients with trauma as the reason for intubation was higher in the difficult intubation group than in the non-difficult intubation group ( $9.64 \%$ vs. $5.06 \%$, respectively; $P=0.120)$. The most common main indication for intubation was failure of oxygenation and ventilation, which nearly range in both groups. With respect to the method of intubation, the number of patients who underwent rapid-sequence intubation with a neuromuscular blockade agent before intubation was significantly higher in the nondifficult intubation group than in the difficult intubation group $(56.10 \%$ vs. $18.10 \%$, respectively; $P=$ 0.001). The difficult intubation group had a significantly higher number of intubation attempts than the non-difficult intubation group (mean number of attempts: 2 vs. 1, respectively; $P<0.001$ ) and a higher rate of failed intubation ( $66.27 \%$ vs. $9.93 \%)$.

The indicators of difficult intubation were facial trauma, large incisors, a beard or mustache, a large tongue, limited mouth opening, a short hypomental distance, a short thyrohyoid distance, poor neck mobility, an obstructed airway, a mask seal, obesity, advanced age, no teeth, and stiff lung. The difficult intubation group had a higher number of patients with all predictors than the non-difficult intubation group. Table 2 shows the results of the multivariable stepwise backward logistic regression analysis, including variables associated with the prediction of difficult intubation. The variables from Table 1 with a P-value of $<0.05$ were included in the initial model analysis. The final model contained the significant predictors of difficult intubation with a P-value of $<0.001$. Each of the significant predictors was assigned a score based on its beta coefficient value, including limited mouth opening (1 point), a large tongue (2 points), poor neck mobility (3 points), an obstructed airway (4 points), and a short hypomental distance (5 points). The difficult airway assessment score model with a score ranging from 0 to 15 was then created and applied to all patients.

The AuROC was $89 \%(95 \% \mathrm{Cl}, 0.860-0.926)$ for the ability of the clinical risk score to predict difficult intubation (Figure 2). The data distribution measures presented in Figure 3 show the distribution plot of the clinical risk score of difficult intubation $(n=83)$ and non-difficult intubation $(n=534)$. The measures of calibration presented in Figure 4 show the observed risk (circle) and score-predicted risk (solid line) for difficult intubation. The score-predicted risk increased in close association with the observed risk. Finally, the risk scores were categorized into three groups: score of $<0$ (low risk), score of 1 to 4 (moderate risk), and score of 5 to 15 (high risk). The positive likelihood ratio of difficult intubation in the high-risk group was 7.62. The risk score was named the MONTH Airway Assessment Score.

\section{Discussion}


As confirmed by analysis of anatomical laryngoscopic views, prediction of difficult intubation in the emergency setting is clinically challenging. Underprediction can delay further management of patients and preparation of alternative airway equipment, and repeated intubation attempts are associated with an increased risk of adverse events such as cardiac arrest, arrhythmia, regurgitation, and airway trauma. ${ }^{14-16}$

Management of difficult intubation in the ED has been less thoroughly studied than that in the operating room. Several difficult intubation prediction scores have been less reported in Asian countries for determining the risk of difficult intubation in the ED setting. Several small studies in Thailand focused on the patients' characteristics, intubation methods, and success rates on the first attempt. ${ }^{19,23,24}$ However, they had limited information regarding predictors of multiple attempts at intubation of patients with difficult airways in the ED setting.

One study showed that the proportion of difficult intubations in the ED setting was $5.4 \%$ to $27 \%,{ }^{6-8}$ which was higher than the incidence of elective intubation in the operating room setting $(0.3 \%-$ $13.3 \%) .{ }^{25,26}$ Our study showed a rate of $13.45 \%$, which is similar to that of the prior study. Existing difficult airway prediction tools such as LEMON have been proposed and evaluated, but each of these has limited sensitivity and specificity $\left(23.3 \%\right.$ and $91.3 \%$, respectively, for LEMION). ${ }^{17}$ Furthermore, some assessment predictors were collected from studies in the operative setting. Most of the patients in these studies were awake and cooperative, and they were examined for preoperative preparation by anesthesiologists (in contrast to examination by EPs in the ED setting). The validation of the prior score (obtained by modified LEMON criteria to predict difficult intubation in the ED) showed a high sensitivity and negative predictive value ( $85.7 \%$ and $98.2 \%$, respectively) but a poor specificity and positive predictive value $(47.6 \% \text { and } 8.9 \% \text {, respectively })^{6}$. Conversely, our study demonstrated poor sensitivity (57.8\%) but high specificity (92.7\%). Previous combinations of multivariable risk scores, such as the Naguib score and intubation difficulty scale, ${ }^{27,28}$ have been presented and assessed in the operative setting to improve the ability of beside testing; however, many predictors cannot be used to evaluate critically ill patients in the ED, and these scores also tend to be time-consuming and difficult to apply in clinical practice.

Our simple model, the MONTH Airway Assessment Score, effectively predicted difficult intubation in our study population (AuROC, $0.893 ; 95 \% \mathrm{Cl}, 0.860-0.926$ ). We identified five predictors of difficult intubation similar to those found in previous studies $5,8,19$ : a short hypomental distance, an obstructed airway, poor neck mobility, a large tongue, and limited mouth opening (Table 2). Our findings showed that the weighted combination of these five independent predictors could help to discriminate between patients with and without difficult intubation among adults undergoing intubation by either conventional direct laryngoscopy or indirect laryngoscopy in the ED. Our score is also a more user-friendly probability score that can be used without the patient's cooperation. Difficult intubation was found in patients with suspected difficult airway anatomy who had moderate scores (1-4) or high scores (5-15) (Table 3$)$. A MONTH Airway Assessment Score of $>5$ points indicates a risk of difficult intubation, and clinicians 
should immediately consult a specialist for appropriate alternative management. If the score is $>1$ point, difficult intubation should be anticipated and a moderately or more highly experienced intubator should be consulted. This score also provides sufficient justification to allow intubators with low experience (medical students in their last year of training) to encounter difficult intubation conditions.

As noted above, we identified five predictors of difficult intubation similar to those found in previous studies ${ }^{19}$ : a short hypomental distance, an obstructed airway, poor neck mobility, a large tongue, and limited mouth opening (Table 2). However, unlike in other reports, male sex was not a significant predictor of difficult intubation. The lack of statistical significance of male sex may be explained by the unequal ratio of men and women between the difficult intubation and non-difficult intubation groups. The differences in significant predictors between previous studies and our study may be explained by this information not being recorded because of the retrospective data collection.

We found that some data were different from our objective in terms of the observed risk versus difficult intubation prediction score (shown in Figure 4). One patient had a high MONTH Airway Assessment Score (13 points), but this patient had been recorded as having a Cormack-Lehane grade I laryngoscopic view (non-difficult intubation). We could explain this by the fact that different individuals performed the evaluations. This problem could be solved by using a more accurate model, the Percentage of Glottic Opening scale, ${ }^{29}$ to evaluate the anatomical laryngoscopic view.

\section{Limitations}

This study as a few limitations. First, this was a retrospective study. The patients' characteristics and clinical indicators were only taken from their medical records, and patients with incomplete data had to be excluded, limiting the study's accuracy. However, we solved this problem by increasing the capture rate of data collection (97.74\%). Another limitation is that we collected the data from the medical record form completed by the intubator after finishing each intubation, and observer bias might have occurred if the intubation was incorrectly assessed and the patient's indicators of difficult intubation were inaccurate. We minimized this bias by administering patient selection in the exclusion criteria process. We excluded patients who were intubated by individuals with low experience. Finally, this study only included adult patients, whose anatomical appearances differ from those of children. Therefore, the results of this study cannot be applied to children.

In conclusion, the MONTH Airway Assessment Score was associated with a more difficult laryngoscopic view and a decrease in intubation success as defined by endotracheal intubation on the first attempt. These associations persisted despite adjustment for multiple difficult intubation covariables. These data suggest the potential utility of the MONTH Airway Assessment Score as a tool for difficult intubation airway prediction in critically ill patients in the ED setting. It can classify patients into low-, intermediate-, and high-risk subgroups, which will help clinicians improve decision-making on appropriate preparation and alternative management, select the most effective method for intubation, and rescue the emergency airway decision. 


\section{Abbreviations}

EP, emergency physicians; ED, emergency department; AuROC, area under the receiver operating characteristic curve; $\mathrm{Cl}$, confidence interval

\section{Declarations}

\section{Ethics approval and consent to participate}

This study was approved by the Faculty of Medicine, Committee on Human Rights Related to Research Involving Human Subjects, Ramathibodi Hospital, Mahidol University (COA. MURA2020/1869). The need for informed consent was waived by the ethics committee because of the retrospective design.

\section{Consent for publication}

Not applicable.

\section{Availability of data and material}

The datasets used and/or analyzed during the current study are available from the corresponding author on reasonable request.

\section{Competing interests}

The authors declare that they have no competing interests.

\section{Funding}

No funding was obtained for this study.

\section{Authors' contributions}

PP and SS designed the study and developed the protocol. PP was responsible for the data collection. CJ and PS were responsible for the data analysis. PP and SS wrote the manuscript. CY and SW provided the final approval for the current version of the manuscript to be published. $\mathrm{CY}$ agreed to be accountable for all aspects of the work. All authors read and approved the final manuscript.

\section{Acknowledgments}

We thank Angela Morben, DVM, ELS, from Edanz (https://www.edanz.com/ac), for editing a draft of this manuscript.

\section{References}


1. Mort TC. Emergency tracheal intubation: complications associated with repeated laryngoscopic attempts. Anesth Analg. 2004;99:607-613, table of contents.

2. Dunford JV, Davis DP, Ochs M, et al. Incidence of transient hypoxia and pulse rate reactivity during paramedic rapid sequence intubation. Ann Emerg Med. 2003;42:721-728.

3. Schwartz DE, Matthay MA, Cohen NH. Death and other complications of emergency airway management in critically ill adults. A prospective investigation of 297 tracheal intubations. Anesthesiology. 1995;82:367-376.

4. Orebaugh SL. Difficult airway management in the emergency department. J Emerg Med. 2002;22:31-48.

5. Soyuncu S, Eken C, Cete Y, et al. Determination of difficult intubation in the ED. Am J Emerg Med. 2009;27:905-910.

6. Hagiwara $\mathrm{Y}$, Watase $\mathrm{H}$, Okamoto $\mathrm{H}$, et al. Prospective validation of the modified LEMON criteria to predict difficult intubation in the ED. Am J Emerg Med. 2015;33:1492-1496.

7. Martin LD, Mhyre JM, Shanks AM, et al. 3,423 emergency tracheal intubations at a university hospital: airway outcomes and complications. Anesthesiology. 2011;114:42-48.

8. Reed MJ, Dunn MJ, McKeown DW. Can an airway assessment score predict difficulty at intubation in the emergency department? Emerg Med J. 2005;22:99-102.

9. Sagarin MJ, Barton ED, Chng YM, et al. Airway management by US and Canadian emergency medicine residents: a multicenter analysis of more than 6,000 endotracheal intubation attempts. Ann Emerg Med. 2005;46:328-336.

10. Seo SH, Lee JG, Yu SB, et al. Predictors of difficult intubation defined by the intubation difficulty scale (IDS): predictive value of 7 airway assessment factors. Korean J Anesthesiol. 2012;63:491497.

11. Crosby ET, Cooper RM, Douglas MJ, et al. The unanticipated difficult airway with recommendations for management. Can J Anaesth. 1998;45:757-776.

12. Samsoon GL, Young JR. Difficult tracheal intubation: a retrospective study. Anaesthesia. 1987;42:487-490.

13. Langeron $\mathrm{O}$, Cuvillon $\mathrm{P}$, Ibanez-Esteve $\mathrm{C}$, et al. Prediction of difficult tracheal intubation: time for a paradigm change. Anesthesiology. 2012;117:1223-1233.

14. Hasegawa K, Shigemitsu K, Hagiwara Y, et al. Association between repeated intubation attempts and adverse events in emergency departments: an analysis of a multicenter prospective observational study. Ann Emerg Med. 2012;60:749-754.e2.

15. Goto T, Gibo K, Hagiwara Y, et al. Multiple failed intubation attempts are associated with decreased success rates on the first rescue intubation in the emergency department: a retrospective analysis of multicentre observational data. Scand J Trauma Resusc Emerg Med. 2015;23:5.

16. Goto $\mathrm{T}$, Watase $\mathrm{H}$, Morita $\mathrm{H}$, et al. Repeated attempts at tracheal intubation by a single intubator associated with decreased success rates in emergency departments: an analysis of a multicentre 
prospective observational study. Emerg Med J. 2015;32:781-786.

17. Kim C, Kang HG, Lim TH, et al. What factors affect the success rate of the first attempt at endotracheal intubation in emergency departments? Emerg Med J. 2013;30:888-892.

18. Calder I. Identification of the difficult airway. Anaesth Intensive Care Med. 2014;15:355-357.

19. Srivilaithon W, Muengtaweepongsa S, Sittichanbuncha Y, et al. Predicting difficult intubation in emergency department by intubation assessment score. J Clin Med Res. 2018;10:247-253.

20. Roth $D$, Pace NL, Lee $A$, et al. Bedside tests for predicting difficult airways: an abridged Cochrane diagnostic test accuracy systematic review. Anaesthesia. 2019;74:915-928.

21. Ji SM, Moon EJ, Kim TJ, et al. Correlation between modified LEMON score and intubation difficulty in adult trauma patients undergoing emergency surgery. World J Emerg Surg. 2018;13:33.

22. Cormack RS, Lehane J. Difficult tracheal intubation in obstetrics. Anaesthesia. 1984;39:1105-1111.

23. Srivilaithon W. Prospective observational study of emergency airway management in emergency department. J Med Assoc Thai. 2016;99 Suppl 4:S131-S137.

24. Trakulsrichai S, Sundarathiti P, Chalermdamrichai P, et al. An observation study of rapid sequence, awake and sedation-only intubations in an emergency department in Thai patients. J Med Assoc Thai. 2009;92:1022-1027.

25. Williams KN, Carli F, Cormack RS. Unexpected, difficult laryngoscopy: a prospective survey in routine general surgery. Br J Anaesth. 1991;66:38-44.

26. Bellhouse $\mathrm{CP}$, Doré $\mathrm{C}$. Criteria for estimating likelihood of difficulty of endotracheal intubation with the Macintosh laryngoscope. Anaesth Intensive Care. 1988;16:329-337.

27. Adnet F, Borron SW, Racine SX, et al. The intubation difficulty scale (IDS): proposal and evaluation of a new score characterizing the complexity of endotracheal intubation. Anesthesiology. 1997;87:1290-1297.

28. Naguib M, Scamman FL, O'Sullivan C, et al. Predictive performance of three multivariate difficult tracheal intubation models: a double-blind, case-controlled study. Anesth Analg. 2006;102:818-824.

29. O'Loughlin EJ, Swann AD, English JD, et al. Accuracy, intra- and inter-rater reliability of three scoring systems for the glottic view at videolaryngoscopy. Anaesthesia. 2017;72:835-839.

\section{Tables}

Table 1: Clinical Characteristics of Patients with Difficult and Non-Difficult Intubation, and Discrimination Power (AuROC) Under Univariable 


\begin{tabular}{|c|c|c|c|c|c|c|c|c|}
\hline \multirow{3}{*}{ Prognostic factor } & \multicolumn{2}{|c|}{$\begin{array}{l}\text { All } \\
(n=617)\end{array}$} & \multicolumn{2}{|c|}{$\begin{array}{l}\text { Difficult } \\
\text { intubation } \\
(n=83)\end{array}$} & \multicolumn{2}{|c|}{$\begin{array}{l}\text { Non-difficult } \\
\text { intubation } \\
(n=534)\end{array}$} & \multirow{3}{*}{$\begin{array}{l}\mathrm{P}- \\
\text { value }\end{array}$} & \multirow{3}{*}{$\begin{array}{l}\text { AuROC } \\
(95 \% \mathrm{Cl})\end{array}$} \\
\hline & $\mathrm{n}$ & $\%$ & $\mathrm{n}$ & $\%$ & $\mathrm{n}$ & $\%$ & & \\
\hline & \multicolumn{2}{|c|}{ Mean $( \pm S D)$} & \multicolumn{2}{|c|}{ Mean $( \pm S D)$} & \multicolumn{2}{|c|}{ Mean $( \pm S D)$} & & \\
\hline \multicolumn{9}{|l|}{ Characteristic } \\
\hline Age (year), mean (SD) & \multicolumn{2}{|c|}{$\begin{array}{l}68.66 \\
( \pm 17.61)\end{array}$} & \multicolumn{2}{|c|}{$\begin{array}{l}66.99 \\
( \pm 17.01)\end{array}$} & \multicolumn{2}{|c|}{$68.92( \pm 17.70)$} & 0.335 & $\begin{array}{l}0.449 \\
(0.385- \\
0.512)\end{array}$ \\
\hline Male gender & 349 & 56.56 & 53 & 63.86 & 296 & 55.43 & 0.155 & $\begin{array}{l}0.542 \\
(0.486- \\
0.598)\end{array}$ \\
\hline \multicolumn{9}{|l|}{ Glasgow coma scale } \\
\hline $3-8$ & 49 & 7.94 & 6 & 7.23 & 43 & 8.05 & 0.631 & $\begin{array}{l}0.525 \\
(0.477- \\
0.573)\end{array}$ \\
\hline $9-12$ & 105 & 17.02 & 11 & 13.25 & 94 & 17.60 & & \\
\hline $13-15$ & 463 & 75.04 & 66 & 79.52 & 397 & 74.34 & & \\
\hline Traumatic Cause & 35 & 5.67 & 8 & 9.64 & 27 & 5.06 & 0.120 & $\begin{array}{l}0.523 \\
(0.490- \\
0.556)\end{array}$ \\
\hline \multicolumn{9}{|l|}{ Main Indication of intubation } \\
\hline $\begin{array}{l}\text { Failure oxygenation or } \\
\text { ventilation }\end{array}$ & 391 & 63.43 & 56 & 67.47 & 335 & 62.73 & 0.716 & $\begin{array}{l}0.470 \\
(0.415- \\
0.524)\end{array}$ \\
\hline Airway protection & 146 & 23.66 & 20 & 24.10 & 126 & 23.60 & & \\
\hline Anticipated & 66 & 10.70 & 6 & 7.23 & 60 & 11.24 & & \\
\hline Cash airway & 14 & $2.27)$ & 1 & 1.20 & 13 & 2.43 & & \\
\hline \multicolumn{9}{|l|}{ Intubation Method } \\
\hline Direct laryngoscopy & 512 & 82.98 & 67 & 80.72 & 445 & 83.33 & 0.533 & $\begin{array}{l}0.513 \\
(0.468- \\
0.559)\end{array}$ \\
\hline Indirect laryngoscopy & 105 & 17.02 & 16 & 19.28 & 89 & 16.67 & & \\
\hline \multicolumn{9}{|l|}{ Method of intubation } \\
\hline RSI & 314 & 50.97 & 15 & 18.07 & 229 & 56.10 & $<0.001$ & $\begin{array}{l}0.657 \\
(0.608- \\
0.705)\end{array}$ \\
\hline
\end{tabular}


Sedation only, without $\quad \begin{array}{llllll}229 & 37.18 & 62 & 74.70 & 167 & 31.33\end{array}$ paralysis

\begin{tabular}{|lcccccccc|}
\hline No-medical assisted & 69 & 11.20 & 3 & 3.61 & 66 & 12.38 & & \\
\hline Others & 4 & 0.65 & 3 & 3.61 & 1 & 0.19 & & \\
\hline Used of induction drug & & & & & & & & \\
\hline None & 73 & 11.83 & 6 & 7.23 & 67 & 12.55 & 0.038 & $\begin{array}{c}0.547 \\
(0.496-\end{array}$ \\
& & & & & & & $0.598)$ \\
\hline Etomidate & 458 & 74.23 & 62 & 74.70 & 396 & 74.16 & \\
\hline Ketamine & 16 & 2.59 & 3 & 3.61 & 13 & 2.43 & \\
\hline Propofol & 28 & 4.54 & 1 & 1.20 & 27 & 5.06 & \\
\hline Others & 42 & 6.81 & 11 & 13.25 & 31 & 5.81 & \\
\hline Used of paralytic drug & & & & & & & \\
\hline None & 301 & 48.78 & 68 & 81.93 & 233 & 43.63 & $<0.001$ & 0.311 \\
& & & & & & & & $0.262-$ \\
\hline Succinylcholine & 286 & 46.35 & 13 & 15.66 & 273 & 51.12 & \\
\hline Rocuronium & 30 & 4.86 & 2 & 2.41 & 28 & 5.24 & \\
\hline
\end{tabular}

Table 2: Best multiple clinically significant predictors of difficult intonation and non-difficult intubation

Table 3: Score categorized probability groups, Likelihood ratio and $95 \%$ confidence interval of difficult Intubation

\begin{tabular}{|c|c|c|c|c|c|c|c|c|}
\hline \multirow{3}{*}{$\begin{array}{l}\text { Score } \\
\text { categorized } \\
\text { probability } \\
\text { groups }\end{array}$} & \multirow{3}{*}{ Score } & \multirow{2}{*}{\multicolumn{2}{|c|}{$\begin{array}{l}\text { Difficult } \\
\text { intubation } \\
(+)(n=83)\end{array}$}} & \multirow{2}{*}{\multicolumn{2}{|c|}{$\begin{array}{l}\text { Non-difficult } \\
\text { intubation } \\
(-)(n=534)\end{array}$}} & \multirow{3}{*}{ LR+ } & \multirow{3}{*}{$95 \% \mathrm{Cl}$} & \multirow{3}{*}{$\begin{array}{l}\mathrm{P}- \\
\text { value }\end{array}$} \\
\hline & & & & & & & & \\
\hline & & $\mathrm{n}$ & $\%$ & $\mathrm{n}$ & $\%$ & & & \\
\hline Low & 0 & 15 & 3.37 & 430 & 96.63 & 0.22 & $0.14-0.36$ & $<0.001$ \\
\hline Moderate & $1-4$ & 23 & 25.84 & 66 & 74.16 & 2.24 & $1.48-3.39$ & $<0.001$ \\
\hline High & $5-15$ & 45 & 54.22 & 38 & 45.78 & 7.62 & $\begin{array}{l}5.29- \\
10.97\end{array}$ & $<0.001$ \\
\hline \multirow[t]{2}{*}{ Mean (SD) } & & \multicolumn{2}{|c|}{$5.86 \pm 4.05$} & \multicolumn{2}{|c|}{$1.00 \pm 2.36$} & & & $<0.001$ \\
\hline & & \multicolumn{2}{|c|}{$6(3-10)$} & \multicolumn{2}{|c|}{$0(0-0)$} & & & $<0.001$ \\
\hline
\end{tabular}




\begin{tabular}{|c|c|c|c|c|c|c|c|c|}
\hline \multirow{3}{*}{ Prognostic factor } & \multicolumn{2}{|c|}{$\begin{array}{l}\text { All } \\
(n=617)\end{array}$} & \multicolumn{2}{|c|}{$\begin{array}{l}\text { Difficult } \\
\text { intubation } \\
(n=83)\end{array}$} & \multicolumn{2}{|c|}{$\begin{array}{l}\text { Non-difficult } \\
\text { intubation } \\
(n=534)\end{array}$} & \multirow{3}{*}{$\begin{array}{l}P- \\
\text { value }\end{array}$} & \multirow{3}{*}{$\begin{array}{l}\text { AuROC } \\
(95 \% \mathrm{Cl})\end{array}$} \\
\hline & $\mathrm{n}$ & $\%$ & $\mathrm{n}$ & $\%$ & $\mathrm{n}$ & $\%$ & & \\
\hline & \multicolumn{2}{|c|}{ Mean $( \pm S D)$} & \multicolumn{2}{|c|}{ Mean $( \pm S D)$} & \multicolumn{2}{|c|}{ Mean $( \pm S D)$} & & \\
\hline Mean number attempts & \multicolumn{2}{|c|}{$1( \pm 0.7)$} & \multicolumn{2}{|c|}{$2( \pm 1.46)$} & \multicolumn{2}{|c|}{$1( \pm 0.4)$} & $<0.001$ & $\mathrm{n} / \mathrm{a}$ \\
\hline More than 1 attempts & 109 & 17.67 & 55 & 66.27 & 54 & 10.11 & $<0.001$ & $\begin{array}{l}0.781 \\
(0.728- \\
0.834)\end{array}$ \\
\hline Failed intubation & 108 & 17.50 & 55 & 66.27 & 53 & 9.93 & $<0.001$ & $\begin{array}{l}0.782 \\
(0.729- \\
0.834)\end{array}$ \\
\hline \multicolumn{9}{|c|}{ Difficult intubation indicators } \\
\hline Facial trauma & 17 & 2.76 & 9 & 10.84 & 8 & 1.50 & $<0.001$ & $\begin{array}{l}0.547 \\
(0.513- \\
0.581)\end{array}$ \\
\hline Large incisor & 54 & 8.75 & 27 & 32.53 & 27 & 5.06 & $<0.001$ & $\begin{array}{l}0.637 \\
(0.586- \\
0.689)\end{array}$ \\
\hline Beard or mustache & 28 & 4.54 & 13 & 15.66 & 15 & 2.81 & $<0.001$ & $\begin{array}{l}0.564 \\
(0.524- \\
0.604)\end{array}$ \\
\hline Large tongue & 54 & 8.75 & 27 & 32.53 & 27 & 5.06 & $<0.001$ & $\begin{array}{l}0.637 \\
(0.586- \\
0.689)\end{array}$ \\
\hline $\begin{array}{l}\text { Limited mouth } \\
\text { opening }\end{array}$ & 70 & 11.35 & 40 & 48.19 & 30 & 5.62 & $<0.001$ & $\begin{array}{l}0.713 \\
(0.658- \\
0.768)\end{array}$ \\
\hline $\begin{array}{l}\text { Short hypo-mental } \\
\text { distance }\end{array}$ & 73 & 11.83 & 41 & 49.40 & 32 & 5.99 & $<0.001$ & $\begin{array}{l}0.717 \\
(0.662- \\
0.772)\end{array}$ \\
\hline $\begin{array}{l}\text { Short thyro-hyoid } \\
\text { distance }\end{array}$ & 68 & 11.02 & 39 & 46.99 & 29 & 5.43 & $<0.001$ & $\begin{array}{l}0.708 \\
(0.653- \\
0.763)\end{array}$ \\
\hline Poor neck mobility & 41 & 6.65 & 13 & 15.66 & 28 & 5.24 & 0.001 & $\begin{array}{l}0.552 \\
(0.512- \\
0.593)\end{array}$ \\
\hline $\begin{array}{c}\text { Presence of } \\
\text { obstructed airway }\end{array}$ & 88 & 14.26 & 37 & 44.58 & 51 & 9.55 & $<0.001$ & $\begin{array}{l}0.675 \\
(0.620- \\
0.730)\end{array}$ \\
\hline Mask seal & 75 & 12.16 & 25 & 30.12 & 50 & 9.36 & $<0.001$ & $\begin{array}{l}0.604 \\
(0.553-\end{array}$ \\
\hline
\end{tabular}


$0.655)$

\begin{tabular}{|c|c|c|c|c|c|c|c|c|}
\hline Obesity & 79 & 12.80 & 35 & 42.17 & 44 & 8.24 & $<0.001$ & $\begin{array}{l}0.670 \\
(0.615- \\
0.724)\end{array}$ \\
\hline Advanced age & 203 & 32.90 & 42 & 50.60 & 161 & 30.15 & $<0.001$ & $\begin{array}{l}0.602 \\
(0.545- \\
0.660)\end{array}$ \\
\hline No teeth & 75 & 12.16 & 23 & 27.71 & 52 & 9.74 & $<0.001$ & $\begin{array}{l}0.590 \\
(0.540- \\
0.640)\end{array}$ \\
\hline Stiff lung & 28 & 4.54 & 7 & 8.43 & 21 & 3.93 & 0.084 & $\begin{array}{l}0.523 \\
(0.491- \\
0.554)\end{array}$ \\
\hline
\end{tabular}

\begin{tabular}{|c|c|c|c|c|c|c|}
\hline Predictors & Category & OR & $\begin{array}{l}95 \% \text { confidence } \\
\text { interval }\end{array}$ & $\begin{array}{l}\mathrm{P}- \\
\text { value }\end{array}$ & $\begin{array}{l}\text { Beta } \\
\text { coefficient }\end{array}$ & Score \\
\hline \multirow[b]{2}{*}{ Limited Mouth Opening } & No & 1 & Reference & - & - & 0 \\
\hline & Yes & 1.47 & $0.36-6.03$ & 0.590 & 0.39 & 1 \\
\hline \multirow[b]{2}{*}{$\begin{array}{l}\text { Presence of Obstructed } \\
\text { Airway }\end{array}$} & No & 1 & Reference & - & - & 0 \\
\hline & Yes & 5.16 & $2.82-9.46$ & $<0.001$ & 1.64 & 4 \\
\hline \multirow[b]{2}{*}{ Poor Neck mobility } & No & 1 & Reference & - & - & 0 \\
\hline & Yes & 3.59 & $1.48-8.66$ & 0.005 & 1.28 & 3 \\
\hline \multirow[b]{2}{*}{ Large Tongue } & No & 1 & Reference & - & - & 0 \\
\hline & Yes & 1.97 & $0.86-4.51$ & 0.108 & 0.68 & 2 \\
\hline \multirow{2}{*}{$\begin{array}{l}\text { Short Hypo-mental } \\
\text { Distance }\end{array}$} & No & 1 & Reference & - & - & 0 \\
\hline & Yes & 6.19 & $1.52-25.19$ & 0.011 & 1.82 & 5 \\
\hline
\end{tabular}

\section{Figures}




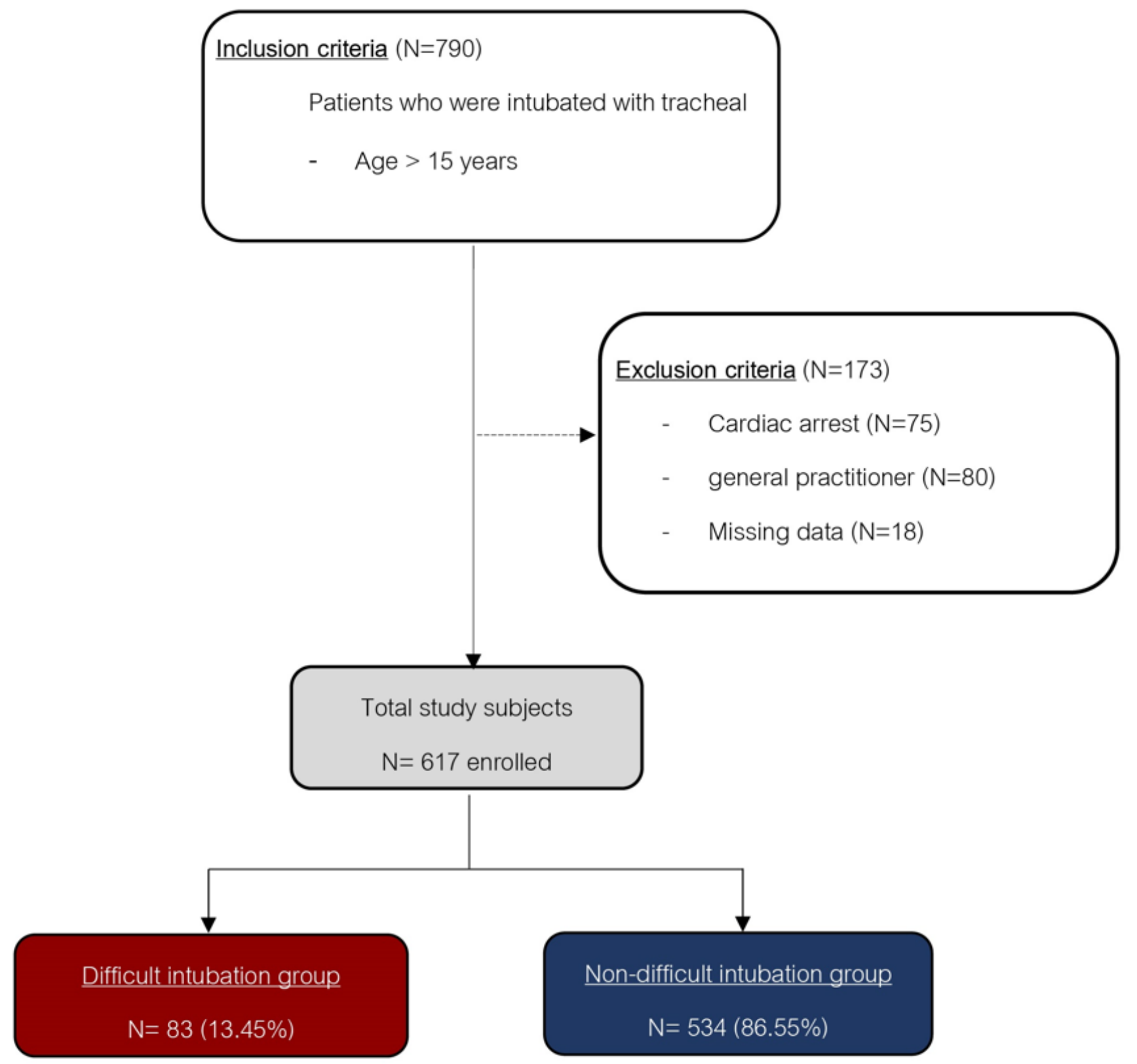

Figure 1

Data collection protocol 




Figure 2

Area under receiver operating characteristic curve (AuROC) of clinical risk score and $95 \%$ confidence interval $(\mathrm{Cl})$ for prediction of difficult intubation 


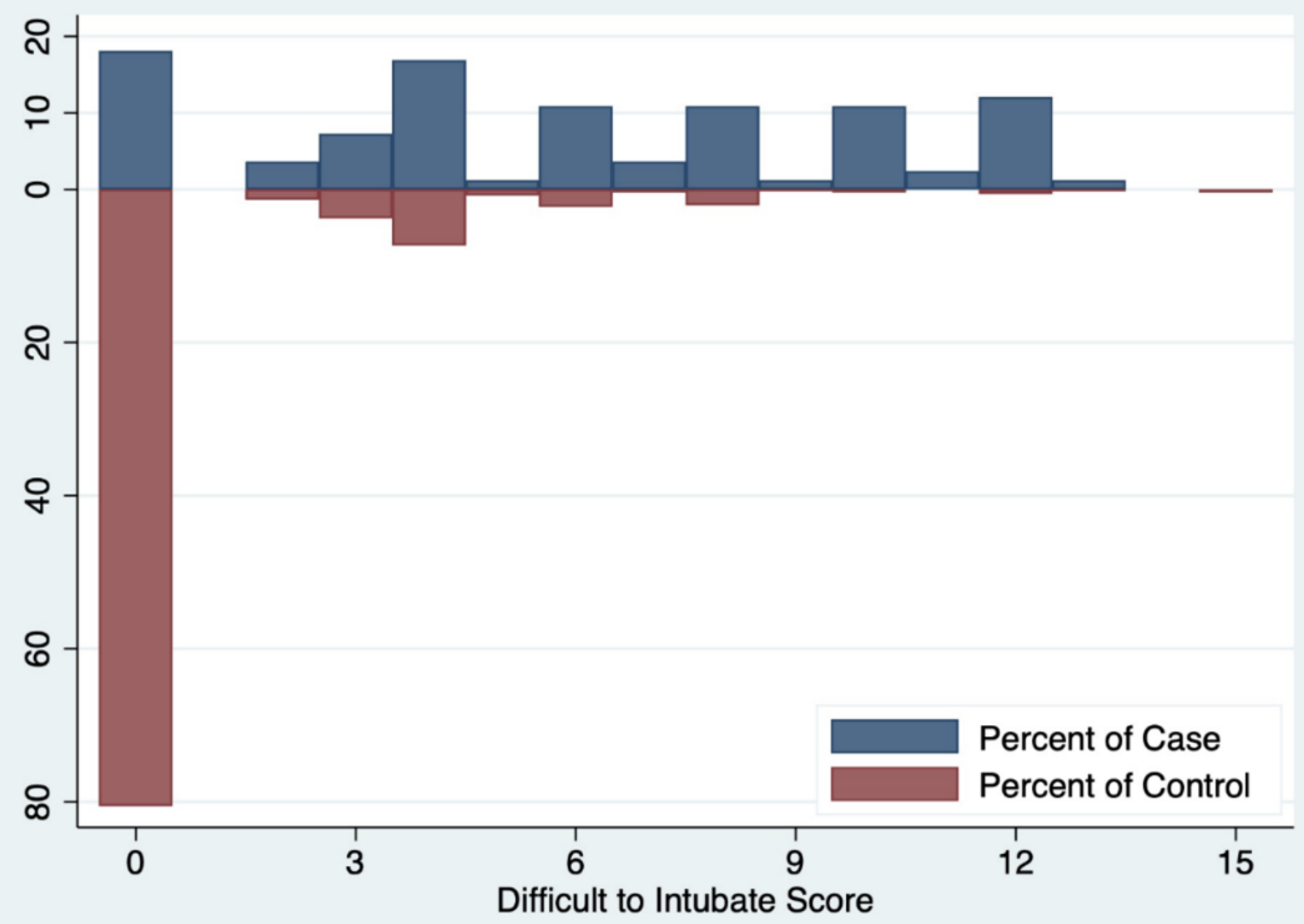

Figure 3

Distribution plot of clinical risk score for difficult intubation $(n=83)$ versus non-difficult intubation $(n=$ 534) 


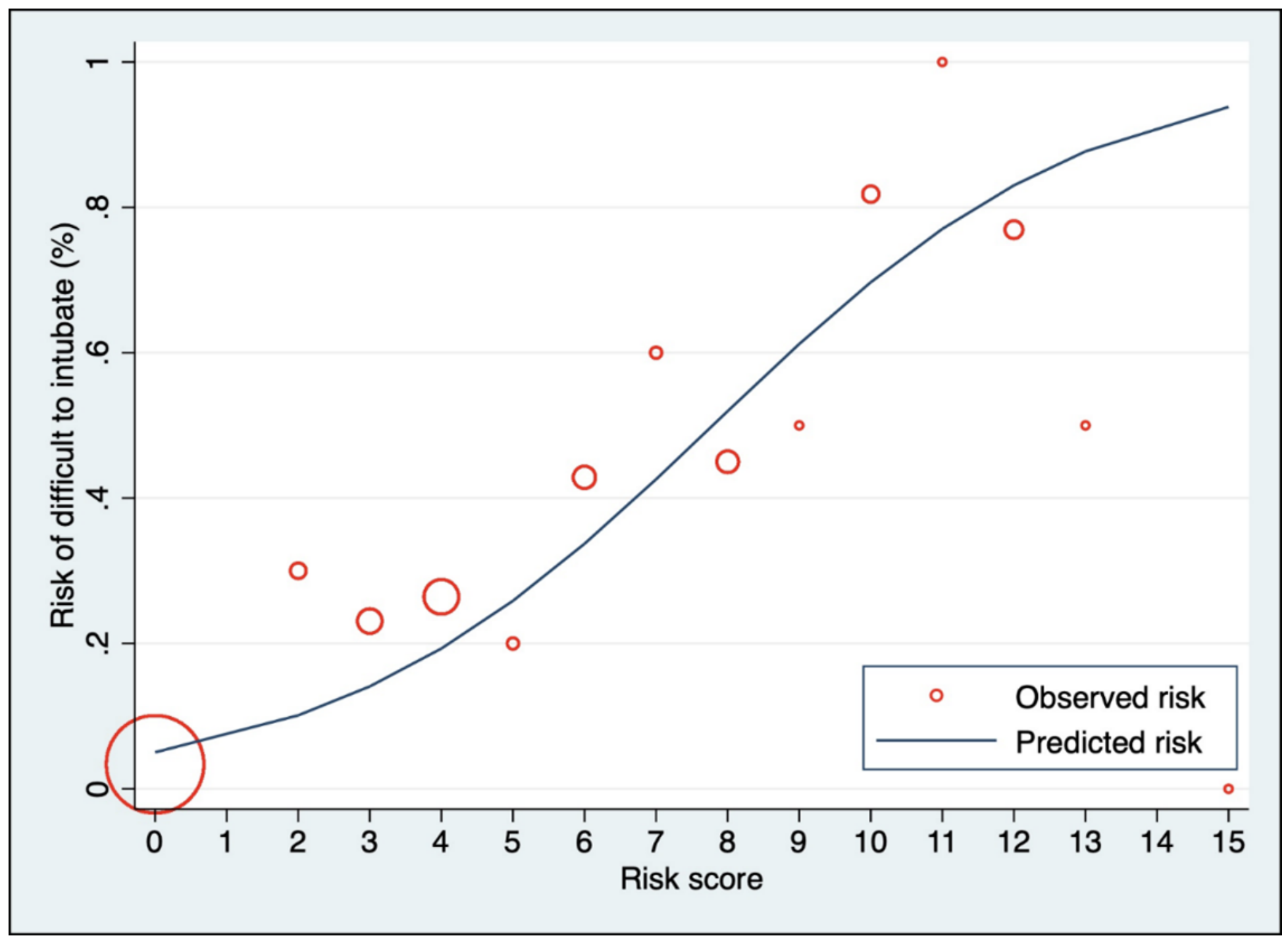

Figure 4

Observed risk (circle) versus score (solid line) of difficult intubation prediction 